Statement. When a prisoner, having completed his sentence, re-offends, public outcry and apportioning of blame often tend to be relatively muted, in comparison with the furore which may follow reoffending by a Special Hospital patient. The rationale employed by society appears to be that once an individual has served the punishment imposed for his crime, then it is correct that he should return to society and if he re-offends agains, the fault lies with him alone. When we hear of recividism rates for prisoners in the order of $80 \%$, this rationale is indeed fortunate for the prison authorities.

The expectation made upon the Special Hospitals is considerably more complex than, as with prisons, merely acting as a vehicle for punishment and containment. Offences must be understood in terms of mental disorders present, and patients maintained in adequate security until such time as these disorders are ameliorated. Not surprisingly such terms of reference result, not infrequently, in longer periods of detention for offenders than would have been occasioned by a prison sentence.

It would appear to me that the Department of Health, as Managers of the Special Hospitals, have a duty to clearly state the purposes and functions of these institutions and bring the recividism statistics of Special Hospital patients into the open, instead of continuing to function, as perceived by the media, behind a 'veil of secrecy'.

Such action might result in more enlightened discussion over the complex problems that the Special Hospitals pose, and perhaps even tempt reporters into making more balanced documentaries than that portrayed in the recent Cook Report. It might also avoid the distasteful scapegoating of Special Hospital Medical Directors, as happened in this particular documentary.

The Norvic Clinic

C. M. GReEN

St Andrew's Hospital

Norwich

\section{Psychiatry and the private sector}

DEAR SIRS

I fear that Dr Turner is looking only at the negative side of psychiatry in the private sector (Psychiatric Bulletin, May 1989,13,249). There is a good deal that the NHS could learn from the independent sector especially in the climate of the Government White Paper, Working for Patients. For example it is possible to treat NHS and private patients in the same surroundings. Between March 1987 and October 1988, 66 of Camberwell's most severely ill patients were admitted to The Priory Hospital. Most of them were on Sections of the Mental Health Act $(2,3,4$ and 136).
The diagnostic categories were as follows:

\begin{tabular}{llcc} 
ICD-9 & \multicolumn{1}{c}{$\begin{array}{c}\text { Camberwell } \\
\text { Health } \\
\text { Authority } \\
\text { (NHS) }\end{array}$} & $\begin{array}{c}\text { Priory } \\
\text { Hospital } \\
\text { (Private) }\end{array}$ \\
\hline 295 & Schizophrenia & $60 \%$ & $16 \%$ \\
296 & Affective psychoses & $29 \%$ & $28 \%$ \\
300 & Neurotic disorders & $5 \%$ & $16 \%$ \\
303 & Alcohol and & & \\
304 & Drug dependence & $6 \%$ & $29 \%$ \\
& Other & $0 \%$ & $11 \%$ \\
\hline
\end{tabular}

As expected, there was a higher proportion of schizophrenic patients in the Camberwell sample and more neurosis, alcohol and substance abuse among the private patients. The scarcity of resources for the in-patient treatment of alcohol problems in the NHS has been the subject of a recent televison programme. The percentage of affective disorders was, however, remarkably similar.

The mean durations of stay of both groups were almost identical: Camberwell patients 24 days; private patients 23 days. The Camberwell patients were treated in the same intensive care setting as the private patients. There are no locked doors and there is not a seclusion room. Only one of the Camberwell patients absconded. There were no suicides. It was apparent that those needing a locked facility for forensic reasons were not appropriate. The one patient who did abscond, did so in his pyjamas. When asked where he was going by a fellow passenger on the bus, he replied "To a pyjama party of course". Another patient, who was on a section of the Mental Health Act, was asked by a Mental Health Act Commissioner "Do you mind being in this hospital?" To which he replied "What? You must think I'm mad!"

The NHS no longer has a monopoly of administrative or innovative ideas. It has been demonstrated that the private sector can also be an appropriate place for registrars and nurses from the NHS to be trained. (Psychiatric Bulletin, April 1989, 13, 199). If the White Paper does nothing else, I hope it will reduce the barriers between the NHS and the independent sector. The Royal College of Psychiatrists appears to recognise this, since there is a representative from the private sector on the College committee discussing the Government White Paper.

The Priory Hospital

DeSMOND KeLLY

\section{London SW15}

\section{Treatment for patients unable to consent}

DEAR SIRS

I wonder how many of my colleagues are aware of the implications of the recent decision of the five Law 